\title{
Syntactic Survey of Determiners in Mo/Deg Language
}

\author{
Anto, Sylvester Kwabena \\ College of Technology Education \\ University of Education, Winneba \\ Post Office Box 1277 \\ Kumasi, Ghana. \\ E-mail: antokwabenasylvester@gmai.com
}

Doi:10.7575/aiac.alls.v.5n.4p.125

URL: http://dx.doi.org/10.7575/aiac.alls.v.5n.4p.125
Received: 10/06/2014

Accepted: 16/07/2014

\begin{abstract}
This study is descriptive, and it is set out to primarily investigate the use and order of determiners in the Mo/Deg language. The study finds answers to the questions, "What determiner types are there in the Mo/Deg language, and in what order do they collocate with the head of the noun phrase?"

Using purposive sampling, the study gathered data from forty (40) literate native speakers of the Mo/Deg language who were also very proficient in English. Short simple English sentences containing noun phrases with pre-determiners of all kind, central determiners of all types, and post-determiners of all kind were designed and given to the respondents to rewrite in Mo/Deg. This was to observe the order of determiners in the language. Also, some of these sentences were given to some staff of the Mo/Deg project of the Ghana Institute of Linguistics, Literacy and Bible Translation (GILLBT) to translate into Mo/Deg since they are deemed to have deeper knowledge of the language. This was to ensure further correctness of the use and order of determiners in the language. The translations comprised the data which was analysed using the Systemic Grammar principles of the NG structure. The results showed that the Mo/Deg language has pre-determiner items and that these pre-determiners are not followed by any other words like adjectives. It further showed that it is permissible for some members of the same pre-determiner class to co-occur. The study further found out that the Mo/Deg language has three types of post-head determiners: the post-head post-determiners, the posthead central determiners, and the post-head pre-determiners. It therefore concluded that the Mo/Deg language has a very complex determiner structure.
\end{abstract}

Keywords: Mo/Deg, determiner, post-head, GILLBT, post-predeterminer, Longoro

\section{Introduction}

The Mo/Deg language belongs to the gur (voltaic) language family and is spoken by over thirty thousand $(30,000)$ people within the Brong-Ahafo and the Northern Regions of Ghana. The two regions are divided by the Black Volta which also separates the two major Mo/Dega towns, New-Longoro (Mantukwa) in Brong-Ahafo Region and Bamboi (Gbambwe) in Northern Region. According to Atta-Akorsah (2004: p13 - 15), the whole Mo/Degland was within the Ashanti Territory till the British colonial government carved out the Northern Territory in 1908, using the Black Volta river as the boundary without due consideration of the fact that one ethnic group had been divided over two territories. The people are therefore split among the Bole District in the North, the Kintampo and the Wenchi municipalities in Brong-Ahafo.

The Mo/Dega in the north speak the Mangom dialect in places such as Bamboi, Jama, Jugboi, Nepui (Kapinta), Tasilima, and a few other places, while those in the south speak the Longoro dialect in places like: Busuama, NewLongoro, Kintampo, Old Longoro, Manchala, Fignyoa (Ahenakom), Kandige, Yaara, Tarbang, Soronuasi, Babatokuma, and other places. Within the Longoro dialect is another brand of the Mangom dialect different from the northern Mangom, and it is spoken in Mansie (Nyambwe). The language is also spoken in places like Adadiem, Dokachina and Bonakire in the Jaman North District of the Brong-Ahafo region, and Dwoboi, Wireke and Zagala in L'Cote d'Ivoire. Deg in the language means "multiply" or a person who speaks Deg and Dega is people who speak Deg.

As a minority language in Ghana, the Mo/Deg language has not seen much of research interest as Twi, Fante, Ewe, Ga, and Dagbani which are in the majority. Although, the Ghana Institute of Linguistics, Literacy and Bible Translation (GILLBT) has started some research into some aspects of the language, their effort needs to be complemented. No research work has been done in the area of determiners in the language. Therefore, there is no gain-saying that this study would not be important and useful to the GILLBT and linguists whose interest lies in syntax.

The intention of the study is to investigate the determiner structures of the Mo/Deg language. For this reason, discussions have been centered on the linguistic items which take up the determiner slot in the noun phrase structure. Therefore, it sought to answer questions like:

(a). what are Mo/Deg determiners like?

(b). what linguistic elements occupy the determiner spot in Mo/Deg? 
(c). what positions do they occupy?

The study is limited to only determiners and their positions with respect to their occurrence with nouns in the language, and the interpretations of such structures.

\section{Methodology}

The population for this study was purposively sampled. This was to identify and select people who could read and write perfectly well in both English and Mo/Deg. Therefore, forty (40) people were identified and selected. Out of the forty people, thirty (30) were selected from six indigenous towns namely: Kandige, Tarbang, Busuama, Mantukwa, Manchala, and Longoro. Five people were selected from each town. This was to cover a large area of where indigenous $\mathrm{Mo} / \mathrm{Deg}$ is spoken and also to have possibly different but acceptable order of the determiners. Again, ten (10) people were selected from among the staff of the Mo/Deg project of GILLBT. This was to ensure that more accurate information was obtained. Short simple English sentences containing noun phrases with pre-determiners, central determiners, and post-determiners were designed and given to the participants to rewrite them in Mo/Deg. The Mo/Deg versions were then analysed syntactically using the Systemic Grammar concept of group structure analysis.

\subsection{The Systemic Grammar Model}

The systemic grammar model sees structure as the arrangement of elements ordered in places. This means that the structure of a unit "has a number of places which can be filled by the next smaller units", Thakur (1998: p 148). Thakur (1998) further states that the group has a place for a headword, a place for a modifier, and a place for a qualifier. This is not to say that all these places must be filled with or occupied by elements every time. However, the headword which according to Morley (1985: p 12) is "the main or focal element of the group on which all other elements in the group depend syntactically" must be filled. The modifier and the qualifier places are optional and "exist at the level of potentials which may or may not be realized". Commenting on the structure of the nominal group (NG), Tarni (2008: $p$ 106 -107) says the systemic grammar model presents it as:

Modifier + Head + Qualifier.

However, since the modifier $(\mathrm{M})$ and the qualifier $(\mathrm{Q})$ may have more than one exponent, the proponents of systemic grammar suggest that the formula for describing groups, thus, the NG, should be rewritten as (M...n) H (Q....n) so that “....n" represents the "possibility of an infinite progression", Thakur (1998) and Verma and Krishnaswamy (1989: p 300 $-302)$.

Therefore, in the case of the determiner structure involving the nominal groups or noun phrase in Mo/Deg, the model will have the following:

$(\mathrm{m})+\mathrm{H}+(\mathrm{q})$

where (m) represents the pre-determiner, $\mathrm{H}$, the noun head, and (q), any of the post-head determiner items.

\subsection{Symbols and Abbreviations Used}

For the purpose of this study, the following symbol(s) and abbreviations have been used.

$$
\begin{aligned}
& \text { ADJ }=\text { adjective } \\
& \text { ART }=\text { article } \\
& \text { Card }=\text { cardinal numeral } \\
& \text { Def }=\text { definite article } \\
& \text { Dem }=\text { demonstrative } \\
& \text { DET } / \text { Det }=\text { determiner } \\
& \text {-GEN/Gen = genitive } \\
& \mathrm{H}=\text { headword } \\
& \text { 1stPL }=\text { first person plural } \\
& 1 \text { stSG }=\text { first person singular } \\
& \text { 2ndSG }=\text { second person singular } \\
& \text { 2ndPL }=\text { second plural } \\
& \text { 3rdSG = third person singular } \\
& \text { 3rdPL }=\text { third person plural } \\
& \text { Indef }=\text { indefinite article } \\
& \text { INTER/Inter }=\text { interrogative } \\
& \mathrm{M} / \mathrm{m}=\text { modifier/modification } \\
& \mathrm{N}=\text { noun } \\
& \mathrm{NG}=\text { nominal group } \\
& \mathrm{NP}=\text { noun phrase }
\end{aligned}
$$


$\mathrm{NUM} / \mathrm{Num}=$ numeral

Ord $=$ ordinal numeral

-PL = plural

$\mathrm{PHC}=$ post-head central determiner

PHP = post-head pr-determiner

PHPD = post-head post-determiner

POSS/Poss $=$ possessive

$\mathrm{Q} / \mathrm{q}=$ qualifier/qualification

QUANT/quant $=$ quantifier

* = unacceptable/ ungrammatical

\section{The Mo/Deg Determiner}

A determiner according to Annan (2000: $\mathrm{p}$ 43) is a word that co-occurs with a noun to convey a variety of semantic contrasts such as quantity or number. Syntactically, the Mo/Deg determiner may follow or precede the noun it determines. For example:

(i) Ya ticha

(ii) Ticha la

The systemic grammar model presents any linguistic item which precedes the headword $(\mathrm{H})$ as $(\mathrm{m})$ and one which follows the $\mathrm{H}$ as (q). Therefore going by this principle of nominal group (NG) or noun phrase analysis, the above constructions can be analysed as follows:

(ia) Ya ticha

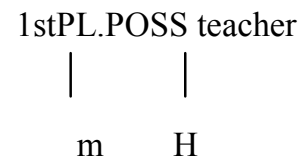

Our teacher (iib) Ticha la

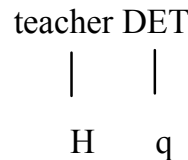

teacher the

The teacher

The words, "Ya" and "la" are determiners in the Mo/Deg language. The Mo/Deg language therefore has both pre-head and post-head determiners as illustrated above.

A determiner may be used in Mo/Deg to identify a person or a thing, or to identify two or more persons or things. For example:

(iii) Ton no<smiles>C[10BH][10BH]C</smiles>

H q

book this

this book

(v) Tolo benkpong<smiles>C[Mg][AsH]C</smiles>

$\mathrm{H} \quad \mathrm{q}$

girl one

one girl (iv) Tone no

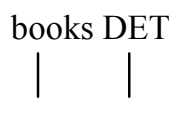

$\mathrm{H} \quad \mathrm{q}$

books these

these books

(vi) Tole batoro

girls NUM

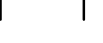

H q

girls three

three girls

In (iii) and (iv) "no" is a determiner and it occurs with the singular noun, "ton" and the plural noun, "tone". Similarly, in (v) and (vi) the words, "benkpong" and "batoro" are determiners which occur with the singular noun, "tolo" and the plural noun, "tole" respectively.

Greenbaum, S. et al (1990: p 72), Wiredu, J. F. (1998: p 79) and Annan, J. C. (2000: p 45) identify three types of determiners in. However, a close study of $\mathrm{Mo} / \mathrm{Deg}$ determiners shows that there are two groups of determiners in the language: pre-determiners and post-head determiners. The post-head determiners are of three types: post-head predeterminers, post-head central determiners, and post-head post-determiners. Example: 
$N$ tone anaare la bwa

$1^{\text {st }} \mathrm{S}$ POSS book-PL four ART all

$\begin{array}{lllll}\mathrm{m} & \mathrm{H} & \mathrm{q} 1 & \mathrm{q} 2 & \mathrm{q} 3\end{array}$

My books four the all

All the four books of mine, or

All my four books

The example above shows that, $N$ is a possessive and a pre-determiner, tone is a noun, thus, headword. This noun-head is then followed by, anaare (a cardinal numeral and post-head post-determiner), then follows la ( an indefinite article and post-head central determiner), finally $b w a$ (all) which is a post-head pre-determiner.

\subsection{Pre-Determiners in Mo/Deg}

In Mo/Deg, the determiners which can occupy the pre-determiner slot according to Anto (2010: p 72 - 77) are the possessive adjectives, the genitives, and the interrogatives (wh-determiners). These according to Quirk, R. et al (1973: $p$ 61 - 62), Greenbaum, S. et al (1990: p 72 - 74), Annan (2000: p 5) and Taylor (2004: p 33) belong to the central determiners. Aarts and Aarts (1982: p 51 - 52) and Greenbaum, S. et al (1990: p 117) identify two subclasses of possessives - those that function 'dependently' as determiners and, 'independently' as 'heads of noun phrases'. These sub-divisions of the possessives pertain to Mo/Deg possessives. However, in Mo/Deg, those which function independently as heads of noun phrase always have the particle or generic noun, 'kon' (thing) attached to the possessive as in: Ya kon (ours or our thing), $B a$ kon (theirs or their thing), etc. Those that function dependently as determiners are $N$ (my), $\mathrm{Ya}$ (our ), $\mathrm{He}$ (your), $\mathrm{O}$ ( its/his/her ), and $\mathrm{Ba}$ ( their ). When they occur with headwords in the pre-modification position, they express possession or ownership. Examples of their use are:

i. He meeh

$2^{\text {nd }}$ SG POSS father<smiles>C[InH]C</smiles>

Your father

(ii) Ba sie

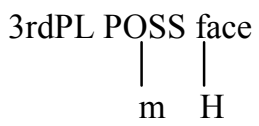

Their face

These possessives in Mo/Deg can occur with count or non-count nouns as in the following examples:

(iii) O dooranar

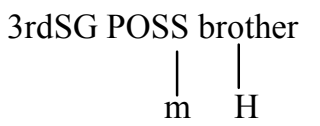

His brothers

(iv) Ya tesom

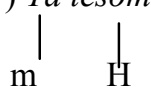

3rdPL POSS kindness

Their kindness

In the examples above, (iii) illustrates the occurrence of the possessive pronoun, ' $O$ ' with a count noun while (iv) exemplifies the occurrence of a non-count noun with the possessive, ' $\mathrm{Ya}$ '.

The genitives are simply nouns or quantifier pronouns without the apostrophe 's. Example: 
i. sukuubie batakaare

student-GEN shirt<smiles>C[InH2]</smiles>

student's shirt

ii. Nomel ton

somebody-GEN book<smiles>C[InH]</smiles>

Somebody's book

Like the possessives, the genitives can occur with count or non-count nouns. For example:

i. Kwame teera

Kwame-GEN sand<smiles>C[InH]</smiles>

Kwame's sand

ii. Nomel nakpale

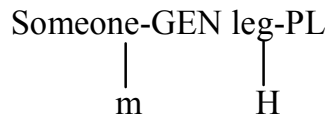

Someone's legs

Examples (i) and (ii) exemplify the occurrence of the genitive with a non-count noun and a count noun respectively. The interrogatives (wh-determiners) which can occur with the noun as pre-determiners are: Ome (whose), Bokwa (what) and Bewe (when or what). However, the interrogative Biso (which), cannot occur as a pre-determiner in the language. Examples of their use are:

(a) Bokwa ton?

INTER book<smiles>[PH2+]c1ccccc1</smiles><smiles>C=CC</smiles>

Det N

what book

(c) Ome bie?

INTER child

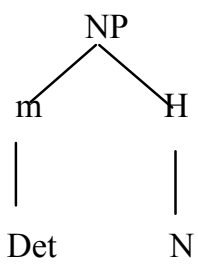

Whose child (b). Bewe sang?

INTER time

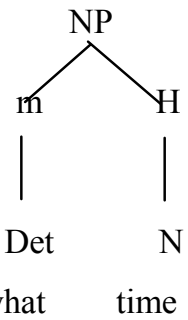

Again, like the possessives and the genitives, the interrogatives can occur with count or non-count nouns as in the following: 
Ome nangaware?

INTER sandal-PL

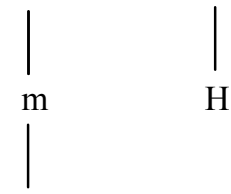

Det
Ome deera?

INTER dream

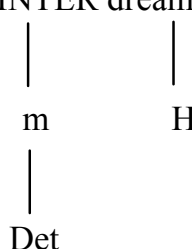

Whose sandals? whose dream?
Bokwa nangaware?

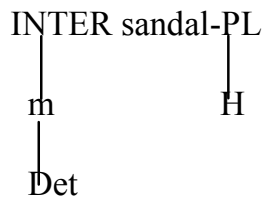

What sandals?
Bokwa deerar?

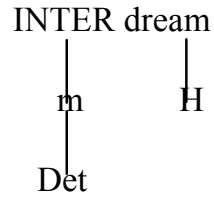

what dream?

From the above examples, 'Ome' occurs with the count noun, 'nangaware' and the non-count noun, 'deera' while 'bokwa,' with the count noun, 'nangaware'and the non-count noun, 'deera'.

It is important to point out that the interrogatives and the possessives (except the quantifier pronouns) can occur together as pre-determiners within the same noun phrase. When they occur the construction is usually interrogative as in the following examples:

i. Ome ya nya?

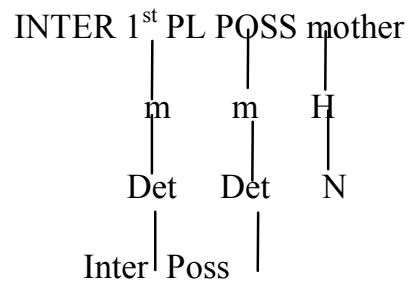

Whose our mother

Who is our mother? ii. He bokwa koo?

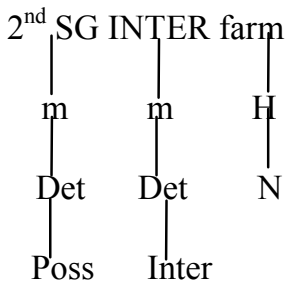

Your what farm

Which is your farm?

In example (i), the interrogative, ome, occurs before the possessive, $y a$, which also occurs before the NG, nya. In (ii), the possessive, he, occurs before the interrogative, bokwa, which also occurs before the noun, koo.

It is also possible in Mo/Deg to have all three pre-determiner items, that is, the interrogatives (except bewe), the possessives, and the genitives (except the quantifier pronouns) occurring in that order as pre-determiners within the same noun phrase structure. However, a reverse of the order or any other order is not an acceptable structure in the language. Example:

iii. Ome he Yao nya?

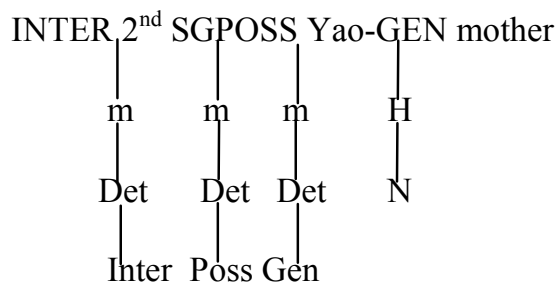

Whose your Yao's mother

Who is Yao's mother? iv. Bokwa ba nime dem

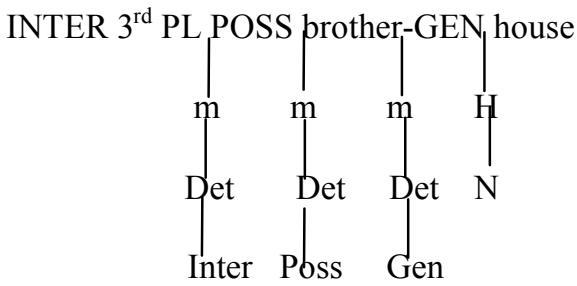

what their brother's house

What about their brother's house?

In example (iii) above, we notice that the interrogative, ome, occurs before the possessive, he, which in turn occurs before the genitive, Yao, which also comes before the NG, nya. In (iv), we have the same order, thus, the interrogative, bokwa, and then the possessive, $b a$, which is followed by the genitive, nime and then the NG, dem. 
It is therefore wrong to have the following order:

* He ome Yao nya?

* Nime ba bokwa dem?

Again, the possessives and the genitives (except the quantifier pronouns) can occur as pre-determiners within the same noun phrase in the Mo/Deg language. However, the order is fixed and must be possessives first before genitives and not the other way round. Example:

v. Ya mee koo

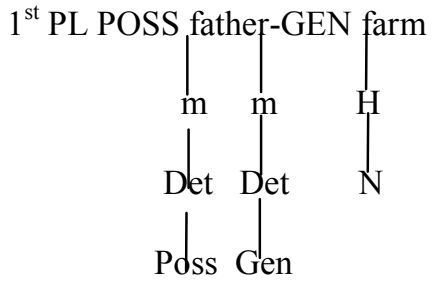

Our farther's farm vi. Ba dam dem

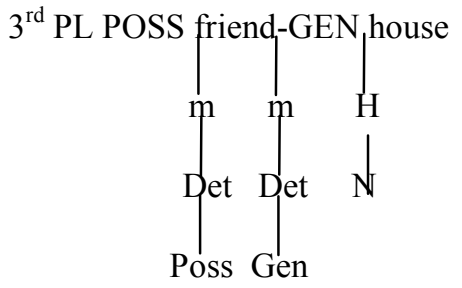

Our friend's house

In examples (v) and (vi), the possessives, ' $y a$ ' and ' $b a$ ' come before the genitives 'mee' and 'dam' which in turn come before the nouns ' $k o o$ ' and 'dem' respectively.

\subsection{Post-head Determiners in Mo/Deg}

These are determiners which occur after the noun in the Mo/Deg noun-phrase structure. Again, for example:

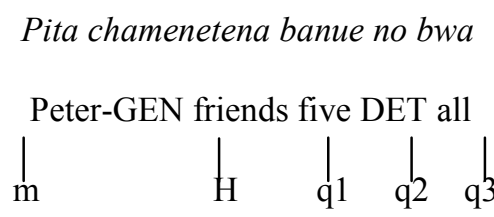

Peter's friends five these all

All these five friends of Peter, or

All Peter's five friends.

The example above shows that, Peter is a genitive and a pre-determiner, chamenetena is a noun, thus, headword. This noun-head is then followed by, banue (a cardinal numeral and post-head post-determiner), then follows no ( a demonstrative pronoun and post-head central determiner), finally $b w a$ (all) which is a post-head pre-determiner. We can therefore identify three types of post-head determiners: post-head post-determiners, post-head central determiners, and post-head pre-determiners.

\subsubsection{Post-head Post-determiners}

These are equivalent to the English post-determiners except for their positions relative to the noun. Post-determiners are linguistic items which according to Greenbaum, S. et al (1990: p 76) "take their place immediately after determiners..." Quirk, R. et al (1973: p 65) says post-determiners are "items which must follow determiners but precede adjectives in the pre-modification structure..." of the noun phrase. Similarly, Mo/Deg post-head post-determiners are linguistic items which occur between determiners and adjectives after the noun head. Example:

Kara pong neete la Stool/chair ADJ NUM DET

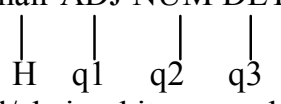

Stool/chair white second the

The second white stool/chair

We notice from the noun phrase above that, Kara, which is the head word is followed by the adjective, pong, which is also followed by the ordinal numeral, neete which is a post-determiner in English language but a post-head postdeterminer in Mo/Deg due to its position after the head word. $L a$ is an article and a post-head central determiner, but a central determiner in English.

The linguistic items which take up the post-head post-determiner slot are the cardinals, the ordinals, the quantifiers, and the interrogative, 'bisoo'. The cardinals include: benkpong (one), ane (two), atoro (three), fi (ten), fi-de-ane (twelve), etc. The ordinal numerals include: logle (first), neete (second), naarete (fourth), fite (tenth), etc. while the quantifiers include: damanta (many), tama (few), fuuh (many), etc. Example: 
(a) kaare atoro

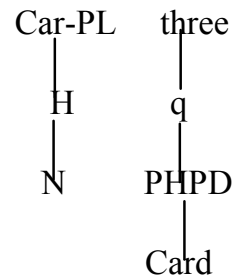

Cars three

Three cars (b) da logle

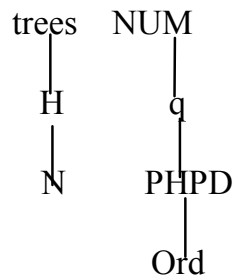

tree first

First tree (c) boohna damanta

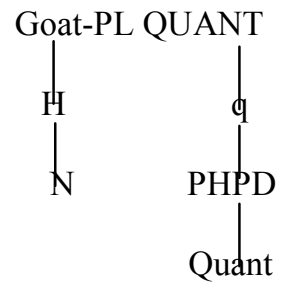

Goats many

Many goats (d) baa bisoo

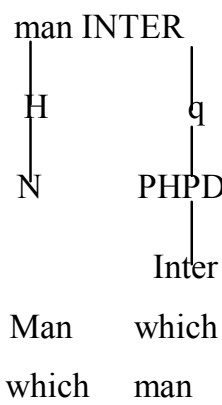

In examples (a) and (b), we have 'atoro' and 'logle' which are a cardinal and an ordinal respectively and they each occupy a post-head post-determiner position, while in examples (c) and (d), we have 'damanta' and 'bisoo' which are a quantifier and an interrogative respectively which also occupy a post-head post-determiner position each.

It is important to mention that 'bisoo' is the only interrogative which does not occur at the pre-determiner position within the noun phrase structure in the Mo/Deg language.

3.2.2 Post-head central determiners

Again, these are similar to the English central determiners which Thakur, D. (1998: p 33) says “...occur after predeterminers and before postdeterminers). But in $\mathrm{Mo} / \mathrm{Deg}$, they occupy the position between the post-head postdeterminers and the post-head pre-determiners after the noun head.

Example:

Baagere anumel la bwa

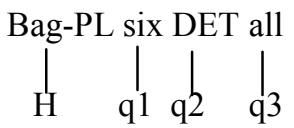

Bags six the all

All the six bags

We notice from the construction above that, la is a post-head central determiner and it is placed between anmel, which is a numeral and a post-head post-determiner and $b w a$, a post-head pre-determiner. The determiners identified by Taylor (2004: p 23), Huddleston, R. (1984: p 233 - 235), and Leech, G. and Svartvik, J. (2002: p 280 - 281) as central determiners in English are post-head central determiners in the Mo/Deg language. They are the definite article, 'la' and the indefinite article, 'bel', and the demonstrative, 'no'. For example:
(a). Bohnoona la
(b) Tooh no

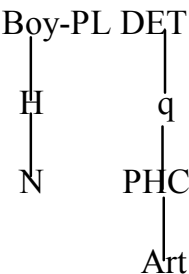

Boys the

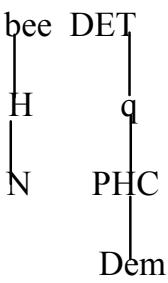

bee this 
In examples (a) and (b) above, we have 'la' and 'no' which are an article and a demonstrative respectively occurring as a post-head central determiner each.

The definite article, 'la', can occur with count nouns (singular and plural) or non-count nouns as in the examples below:

(c) Dea la<smiles>CC(Br)OC1CCCC1</smiles>

house the

The house

(e) Bwaala la

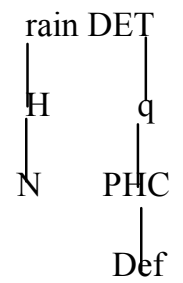

Rain the

The rain (d) Deene la

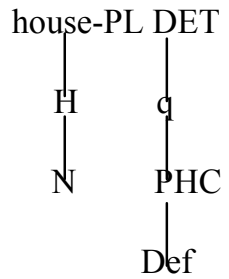

houses the

the houses

In examples (c) and (d) above, we notice that 'la' occurs with singular and plural count nouns respectively; while in (e) it occurs with a non-count noun.

On the other hand, the indefinite article, 'bel' is used with singular count nouns and non-count nouns only. Example:

(f) Bohnoo bel

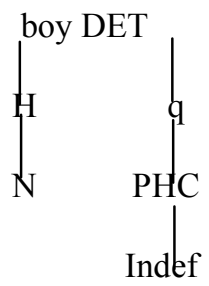

(g) Bwaala bel<smiles>NCC(CBr)OC(CBr)CBr</smiles>

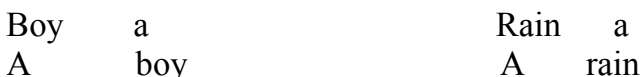

In examples (f) and (g) the indefinite article, 'bel', occurs with 'bohnoo' and 'bwaala', a singular count noun and a noncount noun respectively.

The demonstrative, "no" is the other post-head central determiner. It can occur with a non-count, singular or plural count noun. Example:

i. deera no

ii. Haahna no
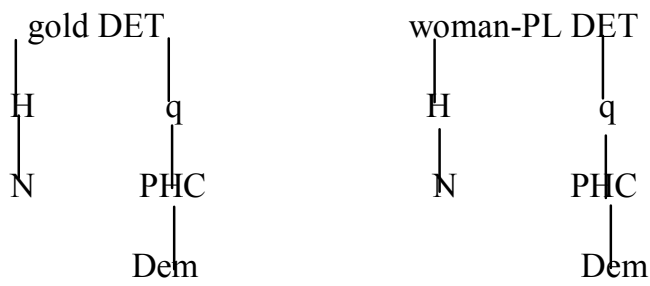

$\begin{array}{lll}\text { dream this } & \text { women these } \\ \text { This dream } & \text { these women }\end{array}$

In examples (i) and (ii), 'no' occurs with 'deera' and 'haahna' which are a non-count noun and a count noun respectively.

The post-head central determiners are mutually exclusive in the Mo/Deg language. 
3.2.3 Post-head Pre-determiners

These determiners occur last in the sequence of determiners qualifying the noun. For example:
Aforomure anuane no ane
Donkey NUM DET DET
Donkey seven these some
Some of these seven donkeys

From the sequence of determiners that follow the head word, Aforomure, in the above utterance, ane, which a post-head pre-determiner occurs last while anuane and no occur first and second respectively in that order after the noun, Aforomure.

There is only one type of the post-head pre-determiner, that is, the quantifier determiners and it includes: pera (half), bwa (all), bane / ane (some). The following are examples of their occurrence:
i Sukuure bwa
ii. Gbene ane

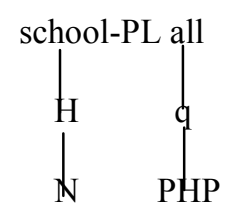

schools all

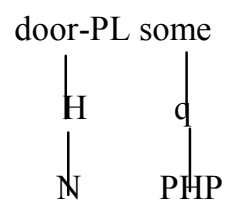

doors some

All schools

Some doors

As a post-head pre-determiner, 'pera' can occur with singular count nouns only and non-count nouns in the language. Example:

$$
\text { i. Yal pera }
$$

Cloth half ii. tesom pera

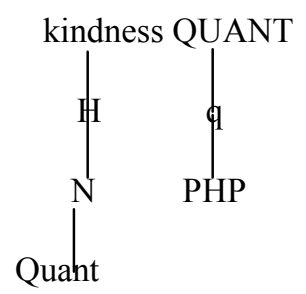

kindness half

Half kindness

In the examples above, 'pera' occurs with 'yal' and 'tesom' which are a singular count noun and a non-count noun respectively.

In the language, 'pera' cannot collocate with a plural noun. We cannot have the following as an acceptable order:

$$
\begin{aligned}
& * \text { Yella pera } \\
& \text { *Nera pera }
\end{aligned}
$$

' $B w a$ ' can occur with either count or non-count nouns. Example:

$$
\text { i. Koo bwa ii.Nera bwa }
$$

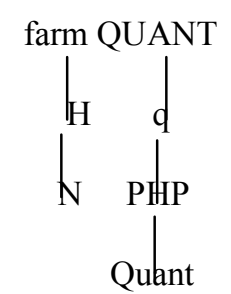

farm all

All the farm

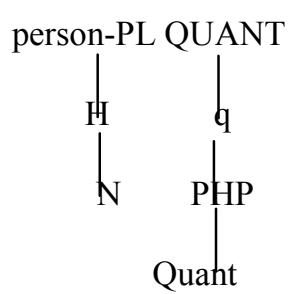

people all

All people 
iii. Nyina bwa

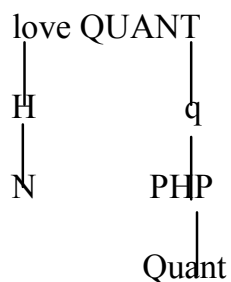

love all

All the love

In example (i), 'bwa' occurs with 'koo', a singular noun, in (ii) it occurs with 'nera', a plural noun, and in (iii) it occurs with 'nyina', a non-count noun.

'Bane' occurs with human plural nouns only while 'ane' with non-human plurals only. Example:

i. Bohnoona bane

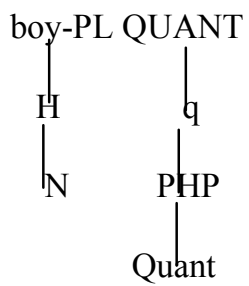

$\begin{array}{ll}\text { boys } & \text { some } \\ \text { Some } & \text { boys }\end{array}$ ii. Nyootena ane

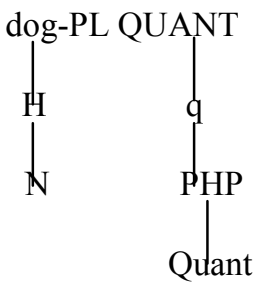

dogs some

Some dogs

From the examples above, 'bane' occurs with 'bohnoona', a human plural noun in (i) while 'ane' with 'nyootena', a non-human plural noun.

It is possible in the language for ' $b w a$ ' to occur next after 'bane', 'ane' or 'pera' within the same noun phrase structure as in the following:

i. Safoone ane bwa

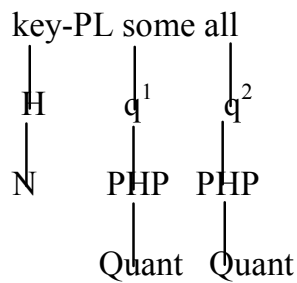

Keys some all

Some of all the keys ii. Bechale bane bwa

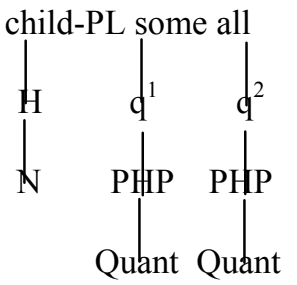

children some all

some of all the children

iii. Da pera bwa.

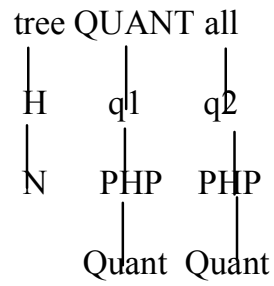

Tree half all

Half of all the tree 


\section{Conclusion}

This study looked at the syntactic positions of the Mo/Deg determiners and identified four groups of determiners in the language: pre-determiners, post-head post-determiners, post-head central determiners, and post-head pre-determiners. The pre-determiners are all the determiner items which occur before the noun in the noun phrase structure and they are the possessives, the genitive, and the interrogative (except bisoo). The post-head post-determiners occur after adjectives but before the post-head central determiners and they are the numerals (both cardinal and ordinals), the quantifiers and the interrogative, bisoo. The post-head central determiners come after the post-head post-determiners and they are the definite and indefinite articles, and the demonstrative, no. Lastly, the post-head pre-determiners, which are the last in the sequence of post-head determiners, have the quantifiers as the only items occupying that slot.

\section{References}

Aarts, F. and Aarts, J. (1982). English syntactic structures: Functions \& categories in sentence analysis. England: Pergamon Press Ltd.

Annan, J. C. (2000). English structure \& usage tody. Ghana: Krosana Book Foundation.

Anto, S. K. (2010). A comparative study of the nominal group structure of English and Mo/Deg. (Unpublished M.Phil. thesis). University of Ghana, Ghana.

Atta-Akosah, T. (2004). Bible translation in christian mission: A case study of the spiritual and socio-cultural impact of the bible translation strategy of the GILLBT on the Dega people of Ghana.(Unpublished M.A. thesis). University of KwaZulu - Natal, South Africa.

Greenbaum, S., Quirk, R., Leech, G. \& Svartvik, J. (1990). A student's grammar of the English language. London: Longman.

Hudleston, R. (1984). Introduction to the grammar of English. Cambridge: Cambrige University Press

Leech, G and Svartvik, J. (2002). A communicative grammar of English. (3 ${ }^{\text {rd }}$ ed). Britain: Pearson Education Limited 136

Morley, G.D. (1985). Systemic grammar. London: Macmillan Publishers Ltd

Quirk, R., Greenbaum, S., Leech, G. and Svartvik, J. (1973). A university grammar of English. India: Addison Wesley Longman

Tarni, P. (2008). A course in linguistics. New Delhi: PHI Learning Private Limited.

Taylor, M. E. (2004). Modern English structure \& usage made simple. ( $2^{\text {nd }}$ ed). Kumasi: Ash-Metro Prints

Thakur, D. (1998). Syntax. New Delhi: Bharati Bhawan.

Verma, S. K. \& Krishnaswamy, N. (1989). Modern linguistics: an introduction. India: Oxford University Press.

Wiredu, J.F. (1998). Organized English grammar. Accra: Academic Publications (Ghana) Limited. 